Published under the Auspices of the International Association for Suicide Prevention (IASP)

\section{Crisis \\ The Journal of Crisis Intervention and Suicide Prevention}

Your article has appeared in a journal published by Hogrefe Publishing. This eoffprint is provided exclusively for the personal use of the authors. It may not be posted on a personal or institutional website or to an institutional or disciplinary repository.

If you wish to post the article to your personal or institutional website or to archive it in an institutional or disciplinary repository, please use either a pre-print or a post-print of your manuscript in accordance with the publication release for your article and our "Online Rights for Journal Articles"

(www.hogrefe.com/journals). 


\title{
Assessment and Management of Suicide Risk in Primary Care
}

\author{
Pooja Saini ${ }^{1}$, David While ${ }^{2}$, Khatidja Chantler ${ }^{3}$, \\ Kirsten Windfuhr², and Navneet Kapur \\ ${ }^{1}$ School of Public Health and Policy, University of Liverpool, UK \\ ${ }^{2}$ Centre for Mental Health and Risk, University of Manchester, UK \\ ${ }^{3}$ School of Social Work, University of Central Lancashire, Preston, UK
}

\begin{abstract}
Background: Risk assessment and management of suicidal patients is emphasized as a key component of care in specialist mental health services, but these issues are relatively unexplored in primary care services. Aims: To examine risk assessment and management in primary and secondary care in a clinical sample of individuals who were in contact with mental health services and died by suicide. Method: Data collection from clinical proformas, case records, and semistructured face-to-face interviews with general practitioners. Results: Primary and secondary care data were available for 198 of the 336 cases (59\%). The overall agreement in the rating of risk between services was poor (overall $\kappa=.127, p=.10$ ). Depression, care setting (after discharge), suicidal ideation at last contact, and a history of self-harm were associated with a rating of higher risk. Suicide prevention policies were available in $25 \%$ of primary care practices, and $33 \%$ of staff received training in suicide risk assessments. Conclusion: Risk is difficult to predict, but the variation in risk assessment between professional groups may reflect poor communication. Further research is required to understand this. There appears to be a relative lack of suicide risk assessment training in primary care.
\end{abstract}

Keywords: suicide, risk assessment, general practitioners, primary care, secondary care

Suicide is a major public health problem internationally and in the UK (World Health Organization, 2012). The majority of individuals are in contact with their general practitioner (GP) prior to suicide (Pearson et al., 2009), particularly those with a mental illness who consult more frequently than other patients (Rodi, Roskar, \& Marusic, 2010). People with a mental illness are at increased risk of suicide (Appleby et al., 2012). As such, GPs are well placed to intervene and potentially improve outcome in patients at risk of suicidal behavior.

To date, suicide prevention in primary care has largely focused on training GPs to identify, assess, and manage suicide risk in patients with a primary diagnosis of depression (Department of Health, 2011; McDowell, Lineberry, \& Bostwick, 2011; Milton, Ferguson, \& Mills, 1999). Risk assessment and management of suicidal patients is emphasized as a key component of care in specialist mental health services, but these issues are relatively unexplored in primary care services. Knowing whether GPs are completing risk assessments, if they are identifying the "right" factors to formulate risk assessments, and whether practice is consistent between GPs and mental health specialists is an important issue. Evidence suggests that different professional groups vary in their risk assessments (Kendall, Taylor, Bhatti, Chan, \& Kapur, 2011). For example, one study found that nonspecialists were more cautious in their risk assessment of patients who had self-harmed than mental health staff were, but no less accurate in predicting repeat episodes (Kapur et al., 2005). Understanding GP procedures for assessing and managing risk in primary care is potentially important for future suicide prevention, but the factors GPs take into account when assessing risk in primary care for patients who go on to die by suicide are relatively unexplored.

The overall aim of the study was to examine risk assessment and management prior to suicide in primary and secondary care in a sample of mental health patients who died by suicide. The specific objectives of this study were to:

1. Compare the level of agreement of risk assessments in primary and secondary care;

2. Investigate the factors associated with high versus low ratings of risk in primary and secondary care;

3. Describe the primary care management including liaison between primary and secondary care for individuals assessed at different levels of risk; and

4. Describe key elements of suicide risk assessment in primary care, including the extent of GP training on risk assessment, and the policies and procedures in place in primary care. 


\section{Method}

\section{Setting and Participants}

This study was carried out in the English National Health Service (NHS). Most of the population is registered with a primary care physician - a GP. Specialist mental health services (generally referred to as mental health trusts) provide care to those seeking treatment. Primary care and specialist treatment, like other services provided by the NHS, is free at the point of use.

The sample for this study included individuals residing in the North West of England who had been in contact with mental health services before death and had died by suicide between January 1, 2003 and June 30, 2007.

\section{Collection of Suicide Data From Mental Health Services}

Mental health service data were collected through the National Confidential Inquiry Into Suicide and Homicide, a well-established national clinical study (Appleby et al., 2012; Appleby et al., 2010). Information on all general population suicides and deaths from undetermined external causes is obtained from the Office for National Statistics. Mental health services identify those people in contact with services in the 12 months before death. Clinical data on these patients are then obtained through questionnaires sent to consultant psychiatrists. The questionnaire comprises multiple sections including: demographic information (e.g., age, sex), clinical history (e.g., primary psychiatric diagnosis, history of self-harm), and clinical management (e.g., treatment and compliance with medication, last contact with mental health services). The inquiry, therefore, provides comprehensive information on a UK-wide case series of all suicides by people in contact with mental health services in the year prior to their death. The ascertainment procedures are robust and the response rates high (over 95\%). Further details are available in previous publications (Windfuhr et al., 2008).

\section{Collection of Primary Care and Interview Data}

Contact details for GPs were obtained from coroner files or administrative departments of NHS Trusts. A retrospective review of primary care medical records (both written and electronic) and, where possible, semistructured interviews were conducted with consenting general practices. A medical records proforma and interview schedules were used to collect data. These were adapted from tools used in previous research (Pearson et al., 2009) and included details of physical and mental health problems reported in all consultations and treatment offered in the year before death (specifically the final consultation), GP views on their concerns for the patient, antecedent factors contributing to death, and factors that could have prevented the death. Information on the mental health treatment a patient received in the 12 months prior to death was determined by direct inquiry from clinicians and also using evidence from the medical records. Additional interview data were collected on GP training on self-harm, suicidal ideation and suicide risk assessments, and the policies GPs followed for patients at risk of suicide. The researcher and GP had access to the written or electronic medical notes in every interview providing a source of contemporaneous data.

All interviews and most case record reviews took place in the GPs' surgeries, but some records were viewed at Primary Care Trust premises. Interviews were audiorecorded where participating GPs consented to this. Case reviews using the proforma took approximately $1 \mathrm{hr}$ and interviews varied between 20 and $40 \mathrm{~min}$.

\section{Ratings of Risk}

For the patients who died by suicide, clinicians in secondary care had estimated the risk at last contact on the inquiry questionnaire as high, moderate, and low or no risk, which we dichotomized for the purposes of the analysis (see next section). Unlike in our previous paper (Pearson et al., 2009) where we looked at immediate risk only, in this study we considered immediate and long-term risk identified by mental health teams. Mental health services rate only a small minority of individuals (approximately 10\%) who have died by suicide as being at high immediate risk at last contact (Appleby et al., 2010). Maximizing the time horizon in this study meant that a greater number of potentially high-risk individuals were included. We also thought that these more inclusive criteria were more comparable with the GPs' ratings (that had no time cut-off). In primary care we used the variable recording of whether GPs had been concerned for their patient's safety prior to death as a proxy measure for high risk (with no concern being taken as a marker of low risk). The primary care risk data were obtained through the GP interviews.

\section{Ethical Approval}

Ethical approval was granted by the North West Research Ethics Committee (REC reference: 02/8/74) for the inquiry as a whole and individual R\&D approvals were obtained from all the relevant Mental Health Trusts included in the study.

\section{Data Analysis}

The secondary care assessments of risk were divided into two categories: (1) perceived moderate and high risk (hereafter referred to as high risk) and (2) perceived low or no risk (hereafter referred to as low risk). We took this approach because previous studies have suggested that even those rated as being at moderate risk have a high incidence of adverse outcomes (Kapur et al., 2005). Many of the independent variables in the questionnaire proformas were in 
Table 1. Factors associated with ratings of suicide risk in primary care

\begin{tabular}{|c|c|c|c|c|}
\hline Variable & $\begin{array}{l}\text { High risk } \\
N=53(\%)\end{array}$ & $\begin{array}{c}\text { Low risk } \\
N=136(\%)\end{array}$ & $\begin{array}{c}p \\
\text { (for difference) }\end{array}$ & $\begin{array}{c}O R \\
(95 \% \mathrm{CI})\end{array}$ \\
\hline \multicolumn{5}{|l|}{ Demographics } \\
\hline \multicolumn{5}{|l|}{ Age } \\
\hline$<39$ years & $14 / 53(27)$ & $51 / 136(38)$ & .722 & $0.86(0.38-1.97)$ \\
\hline $40-53$ years & $24 / 53(45)$ & $38 / 136(28)$ & .084 & $1.98(0.91-4.29)$ \\
\hline$>53$ years & $15 / 53(28)$ & $47 / 136(35)$ & base & base \\
\hline Male & $36 / 53(68)$ & $89 / 136(65)$ & .746 & $1.12(0.57-2.20)$ \\
\hline Not married & $37 / 51(73)$ & $94 / 135(70)$ & 697 & $1.15(0.56-2.36)$ \\
\hline Unemployed/long-term illness & $31 / 49(63)$ & $71 / 128(55)$ & .349 & $1.38(0.70-2.72)$ \\
\hline Living alone & $28 / 53(53)$ & $60 / 136(44)$ & .282 & $1.42(0.75-2.68)$ \\
\hline \multicolumn{5}{|l|}{ Clinical features } \\
\hline Depression & $27 / 53(51)$ & $47 / 136(35)$ & $.040 *$ & $1.97(1.03-3.75)$ \\
\hline Schizophrenia & $8 / 53(15)$ & $28 / 136(21)$ & .389 & $0.69(0.29-1.62)$ \\
\hline Noncompliance with medication & $16 / 50(32)$ & $44 / 125(35)$ & 687 & $0.87(0.43-1.74)$ \\
\hline Recent adverse life events & $21 / 52(40)$ & $44 / 110(40)$ & .963 & $1.02(0.52-1.99)$ \\
\hline Psychiatric inpatient at time of death & $10 / 51(20)$ & $18 / 133(14)$ & .307 & $1.56(0.67-3.65)$ \\
\hline Suicide within 3 months' discharge from inpatient care & $13 / 44(30)$ & $18 / 125(14)$ & $.029 *$ & $2.49(1.11-5.65)$ \\
\hline Suicidal ideas at last contact in primary care & $24 / 46(52)$ & $6 / 126 \quad(5)$ & $<.001 * * *$ & $21.82(8.00-59.51)$ \\
\hline \multicolumn{5}{|l|}{ Behavioral features } \\
\hline History of self-harm & $37 / 53(70)$ & $92 / 130(71)$ & .897 & $0.96(0.48-1.92)$ \\
\hline Patient consulted a GP in the year prior to death following self-harm & $30 / 52(58)$ & $54 / 133(41)$ & $.037 *$ & $2.00(1.04-3.82)$ \\
\hline History of violence & $7 / 51(14)$ & $30 / 133(23)$ & .186 & $0.55(0.22-1.34)$ \\
\hline History of substance misuse & $33 / 52(64)$ & $72 / 135(53)$ & .212 & $1.52(0.79-2.93)$ \\
\hline
\end{tabular}

Note. High risk in this table refers to individuals where the GP was concerned for their safety. ${ }^{*} p=<.05 . * * p=<.01 . * * * p=<.001$.

binary format (presence/absence of factors). For variables providing more than two possible responses, the main factor of interest was selected and the response recoded following a binary format. As some of the responses occurred in only a small number of cases, binary coding provided more reliable estimates of odds ratios (Hawton, Fagg, Platt, \& Hawkins, 1993). The independent variables were listed under the broad headings: demographic factors, clinical features, and behavioral features (see Tables 1 and 2).

Primary care and secondary care data were analyzed separately. Descriptive analyses were used to compare the management and treatment of patients in primary care in the year prior to suicide. Both parametric and nonparametric statistical tests were carried out where appropriate. These included the $\chi^{2}$ test of association, $\kappa$ statistic, and analysis of variance. When percentages are quoted these refer to "valid cases" (i.e., cases for which the relevant information was available). As a result the denominator varies between items. With respect to the interviews, much of the data were presented as simple frequencies.

We carried out forward stepwise logistic regression using SPSS version 20 to compare the factors associated with primary care and secondary care doctors' ratings of the perceived risk of suicide. We were looking at the best-fitting data-driven model for these variables. We report the frequencies, odds ratios, their confidence intervals, and $p$ values.

\section{Results}

\section{Characteristics of the Sample}

Between 2003 and 2007, 336 patient suicides were recorded in the North West of England; approximately $6 \%$ of the entire national sample $(n=5,552)$. GP records were reviewed in $291(87 \%)$ cases and semistructured interviews were completed by 198 (59\%) consenting GPs. Baseline characteristics of the patients are given in Table 3.

In terms of sex, age, civil status, living circumstances, employment status, and clinical characteristics, no significant differences were noted between the patients for whom GP data were obtained and those for whom they were not $(n=45)$. Reasons for nonparticipation of GPs in interviews 
Table 2. Factors associated with ratings of suicide risk in specialist care

\begin{tabular}{|c|c|c|c|c|}
\hline Variable & $\begin{array}{l}\text { High risk } \\
N=69(\%)\end{array}$ & $\begin{array}{c}\text { Low risk } \\
N=101(\%)\end{array}$ & $\begin{array}{c}p \\
\text { (for difference) }\end{array}$ & $\begin{array}{c}O R \\
(95 \% \mathrm{CI})\end{array}$ \\
\hline \multicolumn{5}{|l|}{ Demographics } \\
\hline \multicolumn{5}{|l|}{ Age } \\
\hline$<39$ years & $22 / 69(32)$ & $34 / 101(34)$ & .622 & $1.21(0.57-2.55)$ \\
\hline $40-53$ years & $22 / 69(32)$ & $35 / 101(35)$ & .568 & $1.24(0.59-2.62)$ \\
\hline$>53$ years & $25 / 69(36)$ & $32 / 101(31)$ & base & base \\
\hline Male & $47 / 69(68)$ & $64 / 101(63)$ & .523 & $1.24(0.65-2.36)$ \\
\hline Not married & $49 / 69(71)$ & $71 / 100(71)$ & .998 & $1.00(0.51-1.97)$ \\
\hline Unemployed/long-term illness & $43 / 69(62)$ & $56 / 98(57)$ & .503 & $1.24(0.66-2.33)$ \\
\hline Living alone & $35 / 69(51)$ & $45 / 101(45)$ & .429 & $1.28(0.69-2.37)$ \\
\hline \multicolumn{5}{|l|}{ Clinical features } \\
\hline Depression & $31 / 69(45)$ & $37 / 101(37)$ & .279 & $1.41(0.76-2.63)$ \\
\hline Schizophrenia & $11 / 69(16)$ & $22 / 101(22)$ & .346 & $0.68(0.31-1.51)$ \\
\hline Noncompliance with medication & $27 / 66(41)$ & $26 / 96(27)$ & .067 & $1.86(0.96-3.63)$ \\
\hline Recent adverse life events & $29 / 62(47)$ & $28 / 87(32)$ & .072 & $1.85(0.95-3.63)$ \\
\hline Psychiatric inpatient at time of death & $14 / 67(21)$ & $11 / 100(11)$ & .083 & $2.14(0.91-5.05)$ \\
\hline Suicide within 3 months' discharge from inpatient care & $20 / 61(33)$ & $10 / 92(11)$ & $.001 * * *$ & $4.00(1.72-9.33)$ \\
\hline Suicidal ideas at last contact in primary care & $16 / 67(24)$ & $7 / 100 \quad(7)$ & $.003 * *$ & $4.17(1.61-10.79)$ \\
\hline \multicolumn{5}{|l|}{ Behavioral features } \\
\hline History of self-harm & $57 / 67(85)$ & $59 / 99(60)$ & $.001 * *$ & $3.86(1.77-8.45)$ \\
\hline Patient consulted a GP in the year prior to death following self-harm & $37 / 67(55)$ & $41 / 98(42)$ & .092 & $1.72(0.92-3.21)$ \\
\hline History of violence & $15 / 67(22)$ & $18 / 101(18)$ & .467 & $1.33(0.62-2.87)$ \\
\hline History of substance misuse & $44 / 68(65)$ & $52 / 101(52)$ & .090 & $1.73(0.92-3.25)$ \\
\hline
\end{tabular}

$* p=<.05 . * * p=<.01 . * * * p=<.001$.

where medical records were available were: perceived lack of time; GP had retired or left the practice, no other GP knew the patient; or the GP had died.

\section{Reported Risk: Comparison of Primary Care vs. Secondary Care}

Of the 198 cases, $162(82 \%)$ patients had both primary and secondary data on risk assessment available. In 73 of 162 patients $(45 \%)$, both GPs and mental health specialists rated risk at last contact as low, perhaps particularly surprising given that all of the sample had died by suicide. There was overall agreement in the rating of risk between primary and secondary care for $60 \%$ of patients and disagreement in $40 \%$ (overall $\kappa=.127, p=.10$, strength of agreement: poor). High risk was identified more often by secondary care than primary care clinicians (40\% vs. $30 \%$ ). In only 24 cases (15\% of the suicide deaths) did both sets of clinicians rate the risk as high.

\section{Factors Associated With Risk Prior to Suicide}

Primary Care

Data on GP concerns for safety were available for $189(95 \%$ of 198) cases, of which 53 (27\%) reported concerns for patient safety. Table 3 shows the factors associated with GPs ratings of risk (being concerned or not concerned about the safety of their patient). Four variables (depression; postdischarge care setting; suicidal ideation at last contact with primary care; and primary care consultation following selfharm) were individually associated with perceived risk. Stepwise regression was used; however, the final logistic model included only one variable - suicidal ideation at last contact with primary care $(O R=21.61,95 \% \mathrm{CI}=7.20-64.84$, $p<.001)$ as an independent risk factor of perceived high risk.

\section{Secondary Care}

Data on the reported risk of patients in secondary care were available for a total of 170 cases $(86 \%$ of 198), of which 69 $(41 \%)$ were rated as being at high or moderate risk. Table 2 shows the factors associated with an assessment of higher risk 
Table 3. Baseline characteristics of the 198 patients who died by suicide and were included in the study

\begin{tabular}{|c|c|c|}
\hline Variable & $n$ & $\%$ \\
\hline \multicolumn{3}{|l|}{$\operatorname{Sex}(n=198)$} \\
\hline Male & 130 & 66 \\
\hline Female & 68 & 34 \\
\hline \multicolumn{3}{|l|}{ Age, years $(n=198)$} \\
\hline$<39$ years & 67 & 34 \\
\hline $40-53$ years & 66 & 33 \\
\hline$>53$ years & 65 & 33 \\
\hline \multicolumn{3}{|l|}{ Primary diagnosis $(n=193)$} \\
\hline Schizophrenia/other delusional disorders & 37 & 19 \\
\hline Bipolar affective disorder & 15 & 8 \\
\hline Depressive illness and anxiety disorders & 89 & 46 \\
\hline Drug/alcohol dependence & 18 & 9 \\
\hline Personality disorders/adjustment disorders & 25 & 13 \\
\hline Other (e.g., dementia, organic disorders) & 9 & 5 \\
\hline \multicolumn{3}{|l|}{ Method of suicide $(n=198)$} \\
\hline Self-poisoning & 64 & 32 \\
\hline Carbon monoxide poisoning & 6 & 3 \\
\hline Hanging & 75 & 38 \\
\hline Drowning & 10 & 5 \\
\hline Jumping (e.g., from height, in front of moving object) & 27 & 14 \\
\hline Other (e.g., firearms cutting, burning, suffocation) & 16 & 8 \\
\hline \multicolumn{3}{|l|}{ Clinical characteristics } \\
\hline \multicolumn{3}{|l|}{ History of deliberate self-harm $(n=190)$} \\
\hline Yes & 136 & 72 \\
\hline No & 54 & 28 \\
\hline \multicolumn{3}{|l|}{ Subject to enhanced aftercare $(n=193)$} \\
\hline Yes & 79 & 41 \\
\hline No & 114 & 59 \\
\hline
\end{tabular}

Note. Figures in brackets are number of valid responses for each variable.

in secondary care. Three variables (postdischarge care setting; having suicidal ideas at last contact with secondary care; and a history of self-harm) were individually associated with perceived risk. The stepwise regression model included all three variables as independent risk factors of perceived high risk: postdischarge care setting, $O R=3.28,95 \% \mathrm{CI}=1.29-8.38$, $p=.013$; having suicidal ideas at last contact with secondary care, $O R=3.43,95 \% \mathrm{CI}=1.10-10.70, p=.034$; and a history of self-harm $(O R=3.86,95 \% \mathrm{CI}=1.77-8.45, p=.001$.

\section{Treatment}

\section{Primary Care}

Table 4 examines the association between consultation and treatment in primary care and GPs' ratings of risk. In terms of the consultation data, 186 (98\%) patients consulted in the 12 months prior to their death. Reasons for the final consultation and the type of treatment offered at final consultation were significantly related to GPs' concern for their patient's safety.

\section{Secondary Care}

Table 5 examines the association between consultation and treatment in primary care and secondary care ratings of risk for a total of $170(86 \%)$ patients where information on risk was available from secondary care. In terms of the consultation data, $165(97 \%)$ patients consulted in the 12 months prior to their death. There were no significant differences between the groups. 
Table 4. Treatment and consultation prior to suicide for patients rated as being at high and low risk in primary care

\begin{tabular}{|c|c|c|c|c|}
\hline Variable & $\begin{array}{l}\text { High risk } \\
n=53(\%)\end{array}$ & $\begin{array}{c}\text { Low risk } \\
n=136(\%)\end{array}$ & $\begin{array}{c}p \\
\text { (for difference) }\end{array}$ & $\begin{array}{c}\text { OR } \\
(95 \% \mathrm{CI})\end{array}$ \\
\hline Consulted GP in 12 months prior to death & $52(98)$ & $134(99)$ & .985 & $0.99(0.63-1.56)$ \\
\hline \multicolumn{5}{|l|}{ Consulted for } \\
\hline Psychological reasons & $45(85)$ & $60(43)$ & $<.010^{* *}$ & $1.92(1.17-3.17)$ \\
\hline Psychological and physical reasons & $5(9)$ & $27(20)$ & .147 & $0.48(0.17-1.30)$ \\
\hline Physical reasons & $1(2)$ & $42(31)$ & $.006 * *$ & $0.06(0.01-0.46)$ \\
\hline Other & $1(2)$ & $5(4)$ & .547 & $0.51(0.06-4.50)$ \\
\hline \multicolumn{5}{|l|}{ How long before death was last consultation } \\
\hline$<24 \mathrm{hr}$ & $2(4)$ & $3(2)$ & .563 & $1.17(0.28-10.52)$ \\
\hline$<7$ days & $13(25)$ & $13(10)$ & $.026^{*}$ & $2.57(1.12-5.89)$ \\
\hline $1-4$ weeks & $15(28)$ & $38(28)$ & .970 & $1.01(0.51-1.99)$ \\
\hline 4 weeks to 6 months & $19(36)$ & $67(49)$ & .300 & $0.73(0.40-1.33)$ \\
\hline $6-12$ months & $3(6)$ & $12(9)$ & .505 & $0.21(0.03-1.69)$ \\
\hline At last consultation with GP patient received treatment & $41(77)$ & $111(82)$ & .83 & $0.95(0.59-1.53)$ \\
\hline Medication & $14(26)$ & $86(63)$ & $.008 * *$ & $0.42(0.22-0.80)$ \\
\hline General advice & $4(8)$ & $17(13)$ & .383 & $0.60(0.19-1.88)$ \\
\hline Counseling & $4(8)$ & $8(6)$ & 694 & $1.28(0.37-4.44)$ \\
\hline Referral & $24(45)$ & $9(7)$ & $<.001 * * *$ & $6.84(2.99-15.68)$ \\
\hline \multicolumn{5}{|l|}{ At last consultation with GP patient accepted } \\
\hline Treatment & $29(55)$ & $97(71)$ & .320 & $0.77(0.46-1.29)$ \\
\hline \multicolumn{5}{|l|}{ Mental health treatment offered in 12 months prior to suicide } \\
\hline Medication & $48(91)$ & $126(93)$ & .92 & $0.98(0.62-1.55)$ \\
\hline Inpatient & $26(49)$ & $48(35)$ & .26 & $1.39(0.78-2.47)$ \\
\hline Outpatient (psychiatrist) & $35(66)$ & $93(68)$ & .89 & $0.97(0.58-1.60)$ \\
\hline CMHT (CPN, SW) & $30(57)$ & $84(62)$ & .74 & $0.92(0.54-1.55)$ \\
\hline Alcohol or drug services & $8(15)$ & $22(16)$ & .88 & $0.93(0.39-2.23)$ \\
\hline Psychology & $7(13)$ & $13(10)$ & .51 & $1.38(0.52-3.65)$ \\
\hline Counseling & $4(8)$ & $8(6)$ & 69 & $1.28(0.37-4.44)$ \\
\hline \multicolumn{5}{|c|}{ Mental health treatment accepted in 12 months prior to suicide } \\
\hline Medication & $40(75)$ & $112(82)$ & .72 & $0.92(0.57-1.48)$ \\
\hline
\end{tabular}

Note. High risk in this table refers to individuals where the GP was concerned for their safety. CMHT = Community Mental Health Teams. CPN = Community Psychiatric Nurses. SW $=$ Social Workers.

$* p=<.05$. ** $p=<.01$. *** $p=<.001$.

\section{Policies, Procedures, and Training in the Primary Care Setting}

Only one in four practices had written policies to follow regarding suicide or self-harm (Table 6) and one in five practices was unable to provide any specific information about what policies they followed. A third of the practices had training in place on suicide awareness and self-harm and on risk assessment for suicide. Training was not available to all staff in the practice and tended to be restricted to GPs. A quarter of the GPs had received training on only one occasion during their practicing years, a third received ad hoc training, and a fifth could not report any information about their training.

\section{Discussion}

\section{Main Findings}

This study is the first to our knowledge to compare assessments of risk and characteristics of patients treated by both primary and secondary care in the year prior to suicide. 
Table 5. Treatment and consultation data prior to suicide for patients rated as being at high and low risk in specialist care

\begin{tabular}{|c|c|c|c|c|}
\hline Variable & $\begin{array}{l}\text { High risk } \\
n=69(\%)\end{array}$ & $\begin{array}{c}\text { Low risk } \\
n=101(\%)\end{array}$ & $\begin{array}{c}p \\
\text { (for difference) }\end{array}$ & $\begin{array}{c}O R \\
(95 \% \mathrm{CI})\end{array}$ \\
\hline Consulted GP in 12 months prior to death & $67(97)$ & $98(97)$ & .997 & $1.00(0.65-1.55)$ \\
\hline \multicolumn{5}{|l|}{ Consulted for } \\
\hline Psychological reasons & $44(64)$ & $45(45)$ & .173 & $1.43(0.85-2.40)$ \\
\hline Psychological and physical reasons & $9(13)$ & $21(21)$ & .276 & $0.63(0.27-1.45)$ \\
\hline Physical reasons & $12(17)$ & $27(27)$ & .259 & $0.65(0.31-1.37)$ \\
\hline Other & $2(3)$ & $5(5)$ & .529 & $0.59(0.11-3.10)$ \\
\hline \multicolumn{5}{|l|}{ How long before death was last consultation } \\
\hline$<24 \mathrm{hr}$ & $4(6)$ & $2(2)$ & .222 & $2.93(0.52-16.42)$ \\
\hline$<7$ days & $8(12)$ & $15(15)$ & .594 & $0.78(0.31-1.94)$ \\
\hline $1-4$ weeks & $25(33)$ & $24(24)$ & .195 & $1.52(0.81-2.89)$ \\
\hline 4 weeks to 6 months & $26(38)$ & $49(49)$ & .381 & $0.78(044-1.37)$ \\
\hline $6-12$ months & $7(10)$ & $8(8)$ & .647 & $1.28(0.44-3.70)$ \\
\hline At last consultation with GP patient received treatment & $53(77)$ & $81(80)$ & .855 & $0.96(0.60-1.52)$ \\
\hline Medication & $38(55)$ & $47(47)$ & .530 & $1.18(0.70-2.00)$ \\
\hline General advice & $5(7)$ & $14(14)$ & .233 & $0.52(0.18-1.52)$ \\
\hline Counseling & $5(7)$ & $7(7)$ & .941 & $1.05(0.32-3.43)$ \\
\hline Referral & $11(16)$ & $20(20)$ & .594 & $0.81(0.36-1.79)$ \\
\hline \multicolumn{5}{|l|}{ At last consultation with GP patient accepted } \\
\hline Treatment & $41(59)$ & $70(69)$ & .540 & $0.86(0.52-1.40)$ \\
\hline \multicolumn{5}{|l|}{ Mental health treatment offered in 12 months prior to suicide } \\
\hline Medication & $60(87)$ & $94(93)$ & .765 & $0.93(0.60-1.46)$ \\
\hline Inpatient & $31(45)$ & $37(37)$ & .481 & $1.23(0.70-2.16)$ \\
\hline Outpatient (psychiatrist) & $37(54)$ & $78(77)$ & .150 & $0.69(0.42-1.14)$ \\
\hline CMHT (CPN, SW) & $40(58)$ & $69(68)$ & .516 & $0.85(0.52-1.39)$ \\
\hline Alcohol or drug services & $13(19)$ & $17(17)$ & .778 & $1.12(0.51-2.45)$ \\
\hline Psychology & $10(14)$ & $8(8)$ & .226 & $1.83(0.69-4.87)$ \\
\hline Counseling & $5(7)$ & $4(4)$ & .380 & $1.82(0.47-7.06)$ \\
\hline \multicolumn{5}{|c|}{ Mental health treatment accepted in 12 months prior to suicide } \\
\hline Medication & $51(74)$ & $82(81)$ & 692 & $0.91(0.57-1.45)$ \\
\hline
\end{tabular}

Note . $\mathrm{CMHT}=$ Community Mental Health Teams. $\mathrm{CPN}=$ Community Psychiatric Nurses. $\mathrm{SW}=$ Social Workers.

$* p=<.05 . * * p=<.01 . * * * p=<.001$.

Many patients had been rated as being at low risk of suicide prior to death. The level of agreement with respect to risk assessment in primary and secondary care was poor. In primary care, factors such as depression, care setting (postdischarge), suicidal ideation at last contact with primary care, and primary care consultation following self-harm were associated with GPs being concerned about their patient. Those whom the GPs were concerned about were more likely to have consulted for psychological reasons and were more likely to have been referred to specialist services. In secondary care, factors such as care setting (postdischarge), having suicidal ideas at last contact with secondary care, and a history of self-harm were associated with a rating of high or moderate risk. There were few policies in primary care to guide practice and there was a discernible lack of training on suicidal behavior and risk. We think these findings are of interest to those who plan and provide services and make a strong case for better and more integrated assessment and management of suicide risk.

\section{Methodological Considerations}

Our findings should be interpreted in the context of a number of methodological limitations. Both primary and secondary care clinicians were contacted after death. This may 
Table 6. Policies, procedures, and training in primary care for suicide prevention

\begin{tabular}{|c|c|c|c|}
\hline & $\begin{array}{c}\text { Yes } \\
n(\%)\end{array}$ & $\begin{array}{c}\text { No } \\
n(\%)\end{array}$ & $\begin{array}{c}\mathrm{n} / \mathrm{k} \\
n(\%)\end{array}$ \\
\hline Does this practice follow written policies/protocols regarding suicidal behavior? & $49(25)$ & $136(71)$ & $8(4)$ \\
\hline \multicolumn{4}{|l|}{ Policies and procedures used in primary care } \\
\hline Local (Primary Care Trust) guidelines & $11(22)$ & & \\
\hline National (NICE) guidelines & $5(10)$ & & \\
\hline Use standard measures to monitor patients & $1(2)$ & & \\
\hline Specific mental health protocols & $18(36)$ & & \\
\hline Use national quality framework (QOF) & $4(8)$ & & \\
\hline Not specified & $11(22)$ & & \\
\hline Do the staff at this practice receive training on self-harm or suicide awareness? & $67(35)$ & $123(64)$ & $2(1)$ \\
\hline Is this training available to all staff? & $28(42)$ & $38(58)$ & \\
\hline \multicolumn{4}{|l|}{ How often do staff receive training? } \\
\hline Once & $16(24)$ & & \\
\hline Yearly & $5(8)$ & & \\
\hline Quarterly & $7(10)$ & & \\
\hline Ad hoc local training & $27(40)$ & & \\
\hline Other/not known & $12(18)$ & & \\
\hline Do the staff at this practice receive training on risk assessment for suicide? & $64(33)$ & $124(65)$ & $4(2)$ \\
\hline Is this training available to all staff? & $24(38)$ & $40(62)$ & \\
\hline \multicolumn{4}{|l|}{ How often do staff receive training? } \\
\hline Once & $15(26)$ & & \\
\hline Yearly & $3(5)$ & & \\
\hline Quarterly & $7(12)$ & & \\
\hline Ad hoc in local meetings & $18(31)$ & & \\
\hline Other/not known & $15(26)$ & & \\
\hline
\end{tabular}

Note. $\mathrm{n} / \mathrm{k}=$ not known. NICE $=$ National Institute for Health and Care Excellence. QOF $=$ Quality and Outcomes Framework.

have resulted in recall bias. However, our main aim was to compare specialist and primary care risk assessments and understand the possible reasons for the rating of low risk in patients who went on to die by suicide. This could only be done with a clinical sample of people who were in contact with both mental health and primary care services. A prospective study would not have been feasible. In addition, the researcher and GP had access to the written or electronic medical notes in every interview and were therefore using data that were collected contemporaneously at the time the patient consulted with their GP in order to inform their responses. While the retrospective assessment of risk has its potential weaknesses, it is a well-established methodology, used for example in the UK's National Confidential Inquiry Into Suicide for a number of years. Previous studies have identified variations in accuracy or the amount of detail provided in case records; however, one study comparing GP records and patient self-report questionnaires found similar figures for the mean number of consultations in both sources (Mistry, Buxton, Longworth, Chatwin, \& Peveler, 2005). A systematic review into the quality of computerized medical records found that the recording of consultations on such systems tended to be good (Jordan, Porcheret, \& Croft, 2004). In addition, our primary care data were supplemented by interviews with GPs and our secondary care data were collected directly from the clinicians caring for the patients by means of a dedicated proforma.

It is also possible that some clinicians may have been concerned about their own assessment of suicidal risk and this may have introduced some bias (e.g., with a tendency for some clinicians to perhaps downgrade the estimated level of risk when the patient was last seen). The emotional aspect of suicide and the personal role of the GP in (not) 
preventing the attempt could have contributed to a possible "defensive reporting" of the signals that were missed or wrongly interpreted. In addition it should be borne in mind that risk is dynamic - it changes over time. Some of the differences between primary and specialist services' views of risk might be because the risk assessments were carried out at different times. Equally some of the discrepancies between primary and secondary care ratings of risk could have been due to the slightly different nature of what clinicians were asked - in primary care it was about concerns about the patient's safety.

The sample consisted of people in current, or recent, contact with mental health services from the North West of England and there was no comparison group of those who did not die by suicide, nor of individuals who died by suicide and did not have contact with mental health services. Our risk recognition findings might in some senses represent a best-case scenario, as ours was a clinical sample of patients in contact with services at the time of death. The recognition of risk is likely to have been lower in those not in contact with primary care or mental health services. In this context, we think our findings on the large number of individuals rated as being at low risk prior to death are even more striking.

Our findings may not be representative of the rest of the UK although many of the issues we identified are likely to apply across services. It should also be noted that some of our data are now several years old. As a consequence, some of the study findings might not necessarily reflect current clinical practice.

\section{Clinical and Research Implications}

The assessment of suicide risk is clearly difficult. Part of the challenge is the poor predictive value of assessments and scales, which means that many individuals rated as high risk will not go on to have adverse outcomes (i.e., false positive on the basis of risk assessment; Kapur, 2000; Morriss, Kapur, \& Byng, 2013). In this study we focused on the complimentary issue of false negatives. Similar to previous studies we found that many patients who died by suicide (nearly half the sample) had in fact been rated as being at low risk when they were last seen by their clinicians (Alexopoulos et al., 2009). This "low risk" paradox in patients who go on to die by suicide reflects the problems inherent in predicting low-frequency events, but rapidly changing risk, desensitization to high-risk situations (particularly in specialist care), and recall bias might also contribute (Alexopoulos et al., 2009). In primary care, presentation with physical complaints could mask psychological symptoms and lead to a downgrading of risk.

In this study we also found that there were potentially important differences in the risk assigned to patients in primary and secondary care prior to their death. Poor communication between care settings could account for these findings. Previous studies have highlighted poor communication and sharing of information between general and mental health services (Malone, Szanto, Corbitt, \& Mann, 1995). Strengthening communication and liaison links be- tween care services could lessen discrepancies and contribute to suicide prevention. The rapid improvement of information technology may facilitate both the collection and communication of risk information (Stein, 2002). Systems could flag patients at risk, indicate who is responsible for follow-up care, and may be updated regularly, including for patients who do not attend appointments. Further research to investigate and understand the variation in risk assessment among health professionals may also help to improve practice.

Our data suggest that clinicians do take into account a number of important factors when assessing risk. Comprehensive risk assessments that take into account a wide range of demographic and clinical factors (e.g., employment, living circumstances, age, gender, history of selfharm or substance misuse, physical health) are an important suicide prevention measure (Pearson et al., 2009). Patients who express suicidal ideation at their last consultation but who are rated as low risk (six patients in primary care and seven patients in secondary care in this study) may be an important group in whom to intervene.

We found a comparative lack of training for suicide risk assessment in primary care. This is consistent with previous studies (Gilbert, Adams, \& Buckhingham, 2011; Morriss et al., 2013). It is clear from guidelines (National Institute for Health and Clinical Excellence, 2011) and existing research that the evidence to guide the content and format of suicide risk assessment training is lacking. The use of screening or case finding instruments, for example, the Columbia-Suicide Severity Risk Scale (C-SSRS) that can be used by gatekeepers with minimal training may be a promising avenue to explore further (Posner et al., 2011). Of course, there is the caveat that it will always be extremely difficult to predict low-incidence events like suicide.

\section{Conclusion}

Risk is difficult to predict, but the variation in risk assessment between professional groups may reflect poor communication. There appears to be a relative lack of suicide risk assessment training in primary care. Further research into the assessment and management of suicidal behavior in primary care has the potential to contribute significantly to evidence-based suicide prevention.

\section{Acknowledgments}

We thank all participating GPs and the PCTs who allowed us access to medical records and participated in interviews. The study was carried out as part of the National Confidential Inquiry Into Suicide and Homicide by People With Mental Illness. We thank the other members of the research team: Anna Pearson, Damien DaCruz, Caroline Miles, Harriet Bickley, Jimmy Burns, Isabelle Hunt, Rebecca Lowe, Phil Stones, Pauline Turnbull, Sandra Flynn, 
Cathy Rodway, Alison Roscoe, and Kelly Hadfield. We acknowledge the help of Prof. Louis Appleby, Prof. Jenny Shaw, health authorities, trust contacts, and consultant psychiatrists for completing the questionnaires.

Funding body: The study was initiated while funded by the National Patient Safety Agency and funding was transferred to the Healthcare Quality Improvement Partnership in 2011.

Ethics: North West Multi-centre Research Ethics Committee, 02/8/74.

Authors' contributions: The study was principally designed by PS, KW, and NK but all authors had input into aspects of study design. Ethical approval was obtained by PS and KW. Data collection was carried out primarily by PS, supported by NS and KW. Initial data manipulation was carried out by PS, supervised by DW. Data analysis was carried out by PS and supervised by DW and NK. Clinical input was provided by NK. The manuscript was prepared by PS with supervision from $\mathrm{NK}, \mathrm{KC}$, and $\mathrm{KW}$. All authors commented on drafts of the paper and contributed to the final version.

Conflict of Interest: NK was Chair of the Guideline Development Group for the National Institute for Clinical Excellence (NICE) guidelines for the longer-term management of self-harm and sits on the Department of Health's National Suicide Prevention Strategy Advisory Group.

\section{References}

Alexopoulos, G. S., Reynolds, C. F., III, Bruce, M. L., Katz, I. R., Rave, P. J., Mulsant, B. H., Oslin, D. W., \& Ten Have, T. (2009). Reducing suicidal ideation and depression in older primary care patients: 24-month outcomes of the PROSPECT study. American Journal of Psychiatry, 166, 882-890.

Appleby, L., Kapur, N., Shaw, J., Hunt, I. M., While, D., Flynn, S., Windfuhr, K., \& Williams, A. (2010). National confidential inquiry into suicide and homicide by people with mental illness. Annual report July 2010. Retrieved from http://www. medicine.manchester.ac.uk

Appleby, L., Kapur, N., Shaw, J., Hunt, I. M., While, D., Flynn, S., Windfuhr, K., \& Williams, A. (2012). The national confidential inquiry into suicide and homicide by people with mental illness. Annual report: England, Wales, Scotland and Northern Ireland. Retrieved from http://www.medicine.manchester.ac.uk

Department of Health. (2011). Consultation on preventing suicide in England: A cross-government outcomes strategy to save lives. London, UK: Department of Health.

Gilbert, E., Adams, A., \& Buckhingham, C. D. (2011). Examining the relationship between risk assessment and risk management in mental health. Journal of Psychiatric and Mental Health Nursing, 18(10), 862-868.

Hawton, K., Fagg, J., Platt, S., \& Hawkins, M. (1993). Factors associated with suicide after parasuicide in young people. BMJ, 306, 1641-1644.

Jordan, K., Porcheret, M., \& Croft, P. (2004). Quality of morbidity coding in general practice computerised medical records: A systematic review. Family Practice, 21(4), 396-412.

Kapur, N. (2000). Evaluating risks. Advances in Psychiatric Treatment, 6, 399-406.

Kapur, N., Cooper, J., Rodway, C., Kelly, J., Guthrie, E., \& Mackway-Jones, K. (2005). Predicting the risk of repetition after self-harm: Cohort study. BMJ, 330(7488), 390-395.
Kendall, T., Taylor, C., Bhatti, H., Chan, C., \& Kapur, N. (2011). Longer term management of self harm: Summary of NICE guidelines. BMJ, 343(23), 1-3.

Malone, K., Szanto, K., Corbitt, E., \& Mann, J. J. (1995). Clinical assessment versus research methods in the assessment of suicidal behavior. American Journal of Psychiatry, 152(11), 1601-1607.

McDowell, A. K., Lineberry, T. W., \& Bostwick, J. M. (2011). Practical suicide-risk management for the busy primary care physician. Mayo Clinic Proceedings, 86(8), 792-800.

Milton, J., Ferguson, B., \& Mills, T. (1999). Risk assessment and suicide prevention in primary care. Crisis, 20(4), 171-177.

Mistry, H., Buxton, M., Longworth, L., Chatwin, J., \& Peveler, R. (2005). Comparison of general practitioner records and patient self-report questionnaires for estimation of costs. European Journal of Health Economics, 50, 261-266.

Morriss, R., Kapur, N., \& Byng, R. (2013). Assessing risk of suicide or self harm in adults. BMJ, 347, f4572. doi: $10.1136 /$ bmj.f4572

National Institute for Health and Clinical Excellence. (2011). Self harm: Longer term management. NICE guidelines CG133. Retrieved from http://www.nice.org.uk/Guidance/CG133

Pearson, A., Saini, P., Da Cruz, D., Miles, C., While, D., Swinson, N., Williams, A., Shaw, J., Appleby, L., \& Kapur, N. (2009). Primary care contact prior to suicide in individuals with mental illness. British Journal of General Practice, 59, 826-832.

Posner, K., Brown, G. K., Stanley, B., Brent, D. A., Yershova, K. V., Oquendo, M. A., ... Mann, J. J. (2011). The Columbia-Suicide Severity Rating Scale: Initial validity and internal consistency findings from three multisite studies with adolescents and adults. American Journal of Psychiatry, 168, 1266-1277.

Rodi, P. M., Roskar, S., \& Marusic, A. (2010). Suicide victims' last contact with the primary care physician: Report from Slovenia. International Journal of Social Psychiatry, 56(3), 280-287.

Stein, W. M. (2002). The use of discharge risk assessment tools in general psychiatric services in the UK. Journal of Psychiatric and Mental Health Nursing, 9, 713-724.

Windfuhr, K. L., While, D. T., Hunt, I. M., Turnbull, P., Lowe, R., Burns, J. M., ... Kapur, N. N. (2008). Suicide in juveniles and adolescents in the United Kingdom. Journal of Child Psychiatry and Psychology, 49, 1165-1175.

World Health Organization. (2012). Suicide prevention (SUPRE). Retrieved from http://www.who.int/mental_health/prevention/ suicide/suicideprevent/en/

Received January 21, 2014

Revision received May 14, 2014

Accepted May 27, 2014

Published online September 19, 2014

About the authors

Pooja Saini, BSc, MSc, is a final-year PhD student studying the role of primary care in suicide prevention at the Centre for Mental Health and Risk, University of Manchester, UK. She is also working as a research associate in the Department of Psychological Sciences at the University of Liverpool, UK, in breast cancer research.

David While, BSc, MSc, PhD, works as a research fellow in suicide prevention in the Centre for Mental Health and Risk, University of Manchester, UK, and has been based in this department 
since 2005. He first moved to The University of Manchester in 1998, working as a research associate in the School of Epidemiology and Primary Care.

Dr. Khatidja Chantler is a reader in the School of Social Work at the University of Central Lancashire, Preston, UK, and is a founding member of the Connect Centre for International Research on interpersonal violence and harm. Her research expertise is race, gender, and self-harm.

Kirsten Windfuhr, BA, MA, PhD, is Senior Project Manager and Research Fellow at National Confidential Inquiry into Suicide and Homicide by People with Mental Illness (NCISH), University of Manchester, UK. Her research focuses on suicide and suicide prevention in patients with mental illness.
Navneet Kapur, MD, FRCPsych, is Professor of Psychiatry and Population Health at the University of Manchester, UK, and Honorary Consultant in Psychiatry at Manchester Mental Health and Social Care Trust. His research focuses on the causes and prevention of suicidal behavior.

Pooja Saini

Department of Psychological Sciences

Whelan Building, Room GO4

Brownlow Hill

University of Liverpool

L69 3GS

UK

Tel. +44 151 794-4348

Fax +44 151 794-5537

E-mail pooja.saini@liverpool.ac.uk 